\title{
THE BIGGER PICTURE: CHANGING THE WAY KIDS SEE THE WORLD ONE PHOTO AT A TIME
}

\author{
by \\ Jemel Ganal \\ BA, University of Toronto, Toronto, Ontario, 2016 \\ A thesis \\ presented to Ryerson University \\ in partial fulfillment of the requirements \\ for the degree of Master of Digital Media \\ In the Yeates School of Graduate Studies Ryerson University
}

Toronto, Ontario, Canada, 2018

(C) Jemel Ganal, 2018 


\section{AUTHOR'S DECLARATION FOR ELECTRONIC SUBMISSION OF A THESIS}

I hereby declare that I am the sole author of this thesis. This is a true copy of the thesis, including any required final revisions, as accepted by my examiners.

I authorize Ryerson University to lend this thesis to other institutions or individuals for the purpose of scholarly research.

I further authorize Ryerson University to reproduce this thesis by photocopying or by other means, in total or in part, at the request of other institutions or individuals for the purpose of scholarly research.

I understand that my thesis may be made electronically available to the public. 


\section{ABSTRACT}

THE BIGGER PICTURE: CHANGING THE WAY KIDS SEE THE WORLD ONE PHOTO AT A TIME

by

Jemel Ganal

BA, University of Toronto, Toronto, Ontario, 2016

Master of Digital Media, Ryerson University

This major research project (MRP) works to develop a photography application called Glopal that creates an experience for children to develop an unbiased, empathetic viewpoint of the world. My goal is to help children develop their own, "voice, creativity, agency, and new forms of literacy in a media-saturated era," while creating firsthand experiences of other cultures (Lange \& Ito, 2010, p. 247). Their view of the world is based off of content that is rooted from colonial thinking, which is often biased and stereotypical. Further, by taking their own photographs, children are able to establish their own perspective of the world and foster their intrapersonal dialogue. Children are removed from the "performance" space of social networking sites and can show their true selves through the Glopal app. This essay shows how the Glopal app can be a new digital tool in the development of a child's global citizenship. 


\section{ACKNOWLEDGEMENTS}

I am deeply grateful for the opportunity to have been in the Masters of Digital Media Program this year. I would like to thank my supervisor, Alevtina Naumova, who has provided so much support, encouragement, and belief in my work. This could not have happened without you. To my second reader, Paul Moore, thank you for taking the time to read and provide feedback on my thesis. I would also like to give a special thank you to Dawsyn and Marisa for always being there for me on those tough days and the best days. To Ali and Nada, thank you for always taking care of me. I would also like to thank Angelique Paul, for being a great mentor and friend within this year. To my family, thank you for giving me all the love and support in following my dreams. To Adrian Lim, thank you for being my rock through all of this. Lastly, to the people in my cohort, who I found a family in, thank you for making this year unforgettable. You are what made this program worth it. 


\section{TABLE OF CONTENTS}

Author's Declaration $\quad$ ii

$\begin{array}{ll}\text { Abstract } & \text { ii }\end{array}$

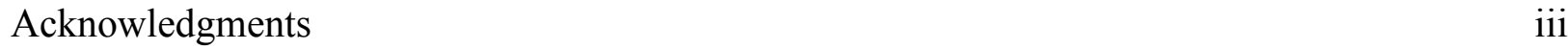

List of Figures

1. Introduction 1

2. Landscape Research 2

3. Literature Review $\quad 4$

3.1. Orientalism 4

3.2. Filter Bubbles and Social Network $\quad 7$

4. Connecting Through Photography 9

5. Glopal Design Decisions: Theory and Design Functions 9

5.1. Photo Missions 10

5.2. Space Explorer 11

$\begin{array}{ll}\text { 5.3. Glopals } & 12\end{array}$

5.4. Design Functions 13

5.5. Parent/Guardian Monitoring 14

6. Research Methodology: Limitations and Future Direction 15

6.1. Limitations Within Research 15

6.2. Research Questions $\quad 15$

$\begin{array}{ll}\text { 6.3. Procedures } & 16\end{array}$

$\begin{array}{ll}\text { 7. Future Direction } & 21\end{array}$

8. Conclusion 22

$\begin{array}{lr}\text { References } & 23\end{array}$ 


\section{LIST OF FIGURES}

FIGURE 1: Mulan Under Cherry Blossom Tree $\quad 5$

$\begin{array}{ll}\text { FIGURE 2: Glopal Photo Missions } & 10\end{array}$

FIGURE 3: Space Theme App Graphics $\quad 11$

FIGURE 4: Glopal Homepage $\quad 12$

$\begin{array}{ll}\text { FIGURE 4: Mission Fluffy } & 13\end{array}$ 


\section{Introduction}

There are vast opportunities of having us work within the digital space to create meaningful connections. We are given the tools to create this global community that allows for us to exceed our ability to connect beyond our local scope. Applications such as Facebook, Instagram, Twitter etc., allow us to see places around the world where we may not have a chance to visit ourselves. As a society, we are curious to know what is out there in the world and yet, our encounters with images of other cultures are generally informed by the demands of the capitalist consumer culture. How we develop our ideas about people of different cultures derive from secondary sources such as news and mainstream media. The problem is that there will always be bias, since each person is unique to their own thoughts. We need to develop tools that help educate children on these bias experiences, allowing for conversations and ideas about global human connection and different cultures to be explored.

This research essay will introduce the idea of children from different countries establishing encounters with another culture, while building unique viewpoints and intercultural bonds. My research works to develop a methodology and a mobile photography application prototype called Glopal, which stands for Global Photo Pal. The application allows for children to post photos based on specific themes, and be able to develop their own, "voice, creativity, agency, and new forms of literacy in a media-saturated era" (Lange \& Ito, 2010, p. 247). The application and the methodology will allow for me to test my assumptions and understand the needs of my users better. The target group that I will be conducting research with are children ages 8-11. They may be, “...unable to, or uncomfortable with expressing themselves in writing; [and] young children tend to express themselves better in actions rather than words" (Lindberg, 
et al., 2014, p. 48). Children are the key targets to this project, since they are the creators of the future social system. They "...have an understanding of themselves, others, and how to negotiate terms of their society" (Serriere, 2010, p. 61). If we can provide them with an experience that will help them develop an unbiased, empathetic viewpoint of the world, that may be the start to improving the way people around the world engage and view one another.

I propose that intimate encounters can be facilitated by focusing on everyday interactions as opposed to the cultural symbols and events. Intimacy and meaningful relationships can be formed by bridging the divide through sharing experiences that are universal. For example, words such as "family", "friendship," and "play," are universal terms that are understood in all countries. If children can connect by understanding the similarities and differences they have with other kids globally, they will be able to establish self-awareness along with empathy for people around the world. We start by shifting the way young people think in order for them to have a more humanizing viewpoint of the world, that will allow a less ignorant mindset than what the mainstream media shows.

\section{Landscape Research}

There have been many programs that have tried to address the issue of the lack of global communication through the form of a global pen pal. Programs such as PenPal School, Skype Classroom, and Google Class. These programs allow children to interact with other cultures in a more intimate way. PenPal School creates common projects for classrooms from around the world to work on together. Teachers are able to pick a project that their class works on with another class in a different country. In order to complete the given task, they have to learn how to collaborate online. This form of collaboration is done through written work and independent research. My program will push the process of reflection beyond text through the use of 
photographs. It will focus on a different kind of interaction and, subsequently, pursue a different kind of a connection. Skype Classroom and Google Class allow for classrooms to talk to other classrooms around the world. They focus a lot more on the live video messaging and having an interaction in real time. The three programs above all work in a group setting rather than a one on one interaction. There are gaps with how they are handling the issue of global connections to different cultures. While they are able to create the experience of a global classroom, these programs fail to achieve the intimate encounter to connect due to the use of group collaboration rather than individual. The way in which these programs are taught, the lessons fall under a more informative experience rather than a reflective one.

Educators should create an environment that calls upon children to use their, "uniquely individual creative state of mind" (Hebert, 2010, p. 149). Because the glopals will be interacting through photography, "the learner moves from 'receiving, filing and storing the deposits' (Freire, 1972) to a more interactive role" (as cited in Childs, 2016, p. 27) in which they are able to compare their own understanding to what they have received, to that of their glopals. This allows for kids to question, re-envision, and think about their everyday life (Serriere, 2010). Following Child (2016), I suggest that this form of communication promotes "critical thinking" and "mutual humanization" (Freire, 1972).

A project by Metropolitan Museum of Art (MET), titled Talking Pictures, explored the idea of photo exchange as a form of intimate interaction. The artists that were involved in the project sent images and brief video "back and forth in a game of pictorial ping-pong" within a 5month period (MET, 2017). One of the pairs, Manjari Sharma and Irina Rozovsky, discovered they were both pregnant and due in April. Their photo conversation ended with a photo of their newborn babies (MET, 2017). What we can take away about this method of intimate interactions 
is how mundane the actions they were documenting were; something as simple as two people taking pictures of their unnamed beds in the morning or the rain on a windowsill, has a way of making people feel closer to one another, as if these moments are not limited by your race, culture, or location. What this experience contributes to my project is a framework understanding of shared experiences that are universal. This proves that intimacy and meaningful relationship building are made through one on one exchanges rather than group exchanges. I hope to bring the same sense of intimacy and relationship building to my research, allowing these children to see how similar we all can be no matter where we're from.

\section{Literature Review}

\section{Orientalism}

Children are being exposed to notions of culture through mass produced symbols and stereotypes, that do not allow for them to connect and learn about people from these different countries without bias. Edward Said (1978), a renowned author, writes of theories on these cultural misrepresentations in his book Orientalism. Orientalism is “... a political vision of reality whose structure promoted the difference between the familiar (Europe, the West, "us") and the strange (the Orient, the East, "them") (Said, 1978, p. 43). This viewpoint is believed to be the source of these misrepresentations of culture, in which the West is seen as superior to those in the East (Said, 1978). Said talks about how “television, the films, and all the media's resources have forced information into more and more standardized molds" (Said, 1978, p. 26). The more these stereotypes are produced, the barrier between "us" and "them" becomes larger. Said (1978) argues that Orientalism is anti-human. How can we respect and empathize with people who we feel superior toward? Kids need more opportunities to be able to explore different cultures without this biased viewpoint. We can see this in places where you least expect it, like in Disney 
films.

Disney has been known for creating films that work towards the Western Gaze, which create "the orient as exotic, mystical and at times barbaric" (Maddox, 2017). This can be seen specifically in films like Aladdin (1992) and Mulan (1998). In Mulan, Disney clearly failed to accurately depict Mulan's Chinese culture. The movie is based in China, yet

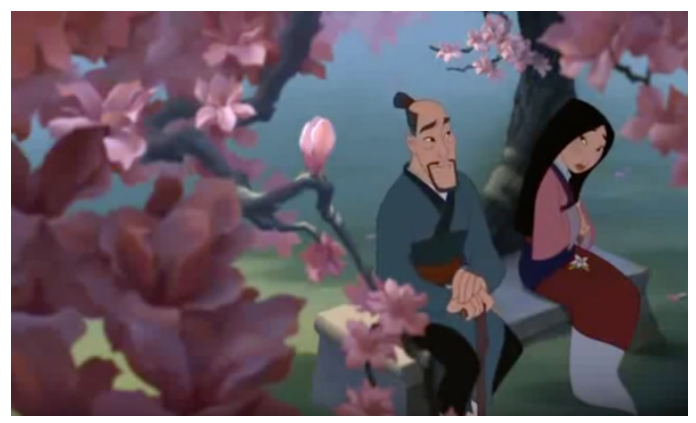

Figure 1: Mulan Under Cherry Blossom Tree Retrieved on August 12 from Mulan (1998). Screenshot by author.

there are scenes that display Japanese motifs. The matchmaking scene with Mulan being dressed as a Geisha is strictly within the Japanese culture, and the slow falling cherry blossom petals that are also a key symbol of Japan are added to create an unrealistic imagery of this "other" land (Maddox, 2017). Disney generalized two very different cultures since they are both within Asia. What this does is equate two different countries into one idea; reducing the cultural significance for both cultures. Essentialism can be defined as "a belief that things have a set of characteristics which make them what they are" (The Oxford Dictionary, 2018). When we essentialize the difference, "stereotypical trait judgments of ethnic and occupational groups, [are] made more extreme and rapid stereotypic judgments [are made] on the basis of limited information about novel groups..." (Haslan, Bastian, et al. 2006, p. 64). With the Glopal app, an essentialist viewpoint is removed since kids will be posting as individuals, representing themselves; they signify who they are rather than the "cultural group" they would be categorized into. The focus shifts onto the child's own ideas, likes, and thoughts rather than what is presumed of them based on predetermined stereotypes.

With Aladdin we can see the exotic and the barbaric. Outside the Sultan's Palace we see the impoverished people of Agrabah. As Aladdin is running through the streets, we come across 
thieves, brothels, and violence. This imagery shows how the Western Gaze views the Middle East. By showing this extreme imagery, it makes the gap between us vs. we even further apart. The barbaric nature of the people in Agrabah illicit fear to the viewers who watch it, creating a villainous stereotype to people who are Middle Eastern. We can view this as Western Postcolonial thinking. Postcolonial theory "addresses matters of identity, gender, race, racism and ethnicity with the challenges of developing a postcolonial national identity...between the powerful and the powerless" (Sawant, 2011, p. 5) Postcolonial literature really shifted the views between the West and the East. Postcolonial writers would write about the precolonial nations before they were colonized, representing them as exotic or the "other" (Sawant, 2011, p. 3). We consistently are surrounded by "stories of inside/outside, self/other, inclusion/exclusion" (McCormack, 2002, p.105). This has created a "presumed divisions between the West and the non-West" (McCormack, 2002, p. 105). What needs to change is to lessen the divide by removing these binary differences. How this can be done, is by creating experiences that are not focused on our differences, but more so on the similarity of our own uniqueness. We are all different, which makes us equal in that sense. With Glopal, children will be able to experience these unique viewpoints from the different images each child posts within each themed mission. This is discussed in more detail further into the essay.

If companies like Disney are producing these inauthentic images and promoting hyperrealistic cultural imagery, how will kids be able to learn without bias? Hyperreality can be defined as "the generation by models of a real without origin or reality" (Baudrillard, 1983, p.166). Hyperreality is created through a reproduction of a the "real", which tends to lose its authentic "realness" since it's been reproduced so many times (Baudrillard, 1983). We are so consumed by the hyperreality that we have lost sight of what is really "real". When media 
recreates ideas and images of stereotypes from different cultures, a reality of these cultures are formed, even though it may not be the "real". Disney and other media sources all contribute to the hyperreality of cultures. Because of the heavily media-saturated environment we live in, it is hard to find the truth in things. But if we can make an effort to learn and gain first hand experiences on discovering different cultures and ideas, we are already a step forward in viewing one another more empathetically.

Imagine a world in which children can view one another as humans, and not jump to judgments based on viewpoints created by those who could not accept anything that is slightly different from the "norm" of society. This understanding of how stereotypes are created and consumed is crucial to the development of Glopal, since it lays the groundwork for what we should not be doing and what to steer clear of, opening our minds to looking at design functions that will allow for unbiased mindset through a digital space.

\section{Filter Bubbles and Social Networks}

Filter Bubbles can be defined as a personalized internet user experience created through an algorithm that is based on information collected from the user online (Pariser, 2011). We need to take away the filter bubble and remove any biased views that would be created from them. With a filter bubble placed on all forms of media consumption, how can one be able to unbiasedly view different viewpoints and ideas? With Glopal, the filter bubble is removed by the removal of captions, and by allowing the kids to openly post within each category. There is no manipulation with the process of capturing photos. There is no algorithm to show specific photos that generate a specific idea. Glopal allows for the child to create their own ideas based on their first-hand experience with the app. 
We can see that children are affected by personal filter bubbles that limit their scope of information on different cultures; when it comes to other cultures, they are often told what to think and believe rather than discovering these learnings themselves. This is another factor that hinders them to be able to expand their mindset. The consequences of the filter bubble are both personal and cultural (Pariser, 2011). With filter bubbles there is a smaller chance at encountering insight and learnings about different cultures, and that is a big problem. Without interaction with ideas from different cultures, we hold ourselves back from "changing our mindset on how we think about the world and ourselves" (Pariser, 2011, p.15). This is why children need an app like Glopal.

Looking at a photo sharing platform like Instagram, we see that there are issues in making an application like Glopal into a social networking app. With Social Networking Sites (SNSs) we enter performative state that is constructed through hyperreality (Baudrillard, 1983). If the Glopal app were to be developed like Instagram, we take away authenticity and focus from each photograph. When we produce these hyperreal depictions of the world, we create in this process a simulation of a reality that strays away from any "authentic" meaning. When people post on social media, they are posting for an audience. So they create the "reality" they want you to see. This again can be understood with how we understand other cultures and countries. Concepts like Orientalism have been developed from the reproductions of reproductions, therefore losing the "reality" of what is true to East Asian Countries.

We want to take children out of an online public space like Instagram, in order to remove the need for an audience, allowing them to shoot authentically rather than put on a performance. Instagram challenges "the authenticity characteristic of citizen journalism and amateur photography, as well as the realism to which professional photojournalism has historically 
subscribed" (Rey, 2015). By allowing children to take these photographs outside of the "performance" space, they can show their true selves and not the person they want others to see. That is a crucial part to this application, because if the children can't be transparent and authentic with themselves and others, the photos won't mean as much.

\section{Connecting With Photography}

They say a picture is worth a thousand words, so why not use it as a means of communication and connection. Photography is at the root of this application since it is one of my passions that I wanted to share and expand upon towards my final project. Photography for kids is used in ways to document “...their lives and as a means of self-expression" (Lange \& Ito, 2010, p. 290). We see this through SNS's such as Instagram and Facebook. Children who were exposed to digital photography within art making media, brought out the child's interpersonal and intrapersonal dialogue (Richards, 2009). Intrapersonal dialogue is communication with oneself that involves acts self awareness such as internal conversations, reflections, or ideating (McLean, S, 2005). Kids gain a sense of intrapersonal dialogue through the photo exchange since they are able to reflect and analyze what other children around the world post. For example, they have the opportunity to reflect on how the word "fluffy" resonates with kids in India or Brazil versus a child in Canada. The act of photography will bring out that intrapersonal reflection, which can be the start to those interpersonal conversations with their friends. The aim for these photographs is to allow kids to literally "view" things differently and change the way they "see" the world. I am relying on the child's innate ability to be able to capture a photograph and to know what to shoot. I do imagine that the opportunity to get more direction with their photography will come, if the application is used in an educational setting and incorporated with a curriculum. Regardless, the main focus is not on the quality of the photos, but what is within 
the photos. By turning kids into media producers by taking photos rather than being media consumers, they have the opportunity to develop their own, "voice, creativity, agency, and new forms of literacy in a media-saturated era" (Lange \& Ito, 2010, p. 247). There is no right or wrong way to take a photograph, and because each person is unique, each photo will be unique as well. That is the beauty with photography; it is that we are able to see the world through someone else's perspective.

\section{Glopal Design Decisions: Theory and Design Functions}

\section{Photo Missions}

The Glopal app has very distinct features that fulfill the goals I am trying to accomplish through the usage of this app. Those goals being, to help children develop self-awareness, empathy, and a global citizenship within the digital space. The first feature are the photo missions. Photo missions are photo categories for kids to post in. So instead of having a feed they can post freely on, kids will be required to post in any of the photo missions listed on the

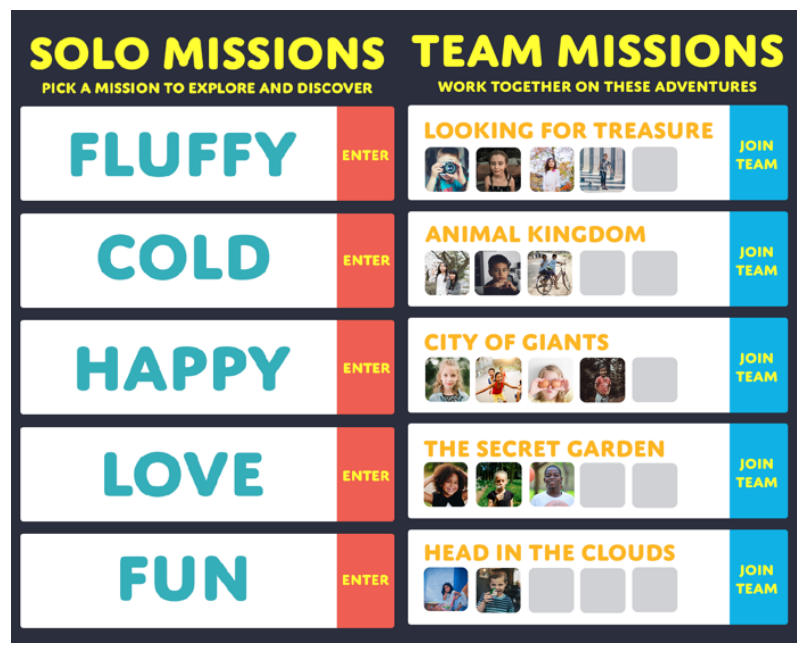

missions page. The goal of the missions is for kids to see how kids from different parts of the world interpret a single word. The reason behind kids focusing on a single word is because it provides constraints on their thought process; "constraints for creativity as barriers that lead to breakthroughs" (Stokes, 2006, p. 7). Kids will be able to fully Figure 2: Glopal Photo Missions analyze and think clearly about what each word means to them, allowing for an authentic and meaningful post. 
There will be two types of photo missions, singular and grouped. The singular photo missions are stand-alone missions where kids can post their pictures pertaining to that word to gain points. The grouped missions are like adventures. Kids will join teams of 5 to complete a grouping of missions that are tied together. In order to move on to the next mission, all team members must post their photo. At the end of the mission, they will be able to visually see the "journey" they went on with their team. This allows for collaboration among the kids and help build bonds, “...civic engagement, social inclusion and other opportunities" as their work together on these photo missions (Lenhart, 2012). We are able to take away stereotypes and bias through these photo missions, allowing for kids to have a more humane and empathetic viewpoint of the world. Since the kids will be focused on posting towards this unified mission, it will help them see just how other kids may see the world. Human development “...is immeasurably enriched and extended through the individual's appropriation and mastery of cultural inheritance as is encountered in activity and interaction with others" (Wells, 2000, p. 54). Whether or not the photos turn out the same or different, this type of photo feed can show kids that the way they see the world, is one of many viewpoints that people have, hopefully allowing them to be a little more open minded.

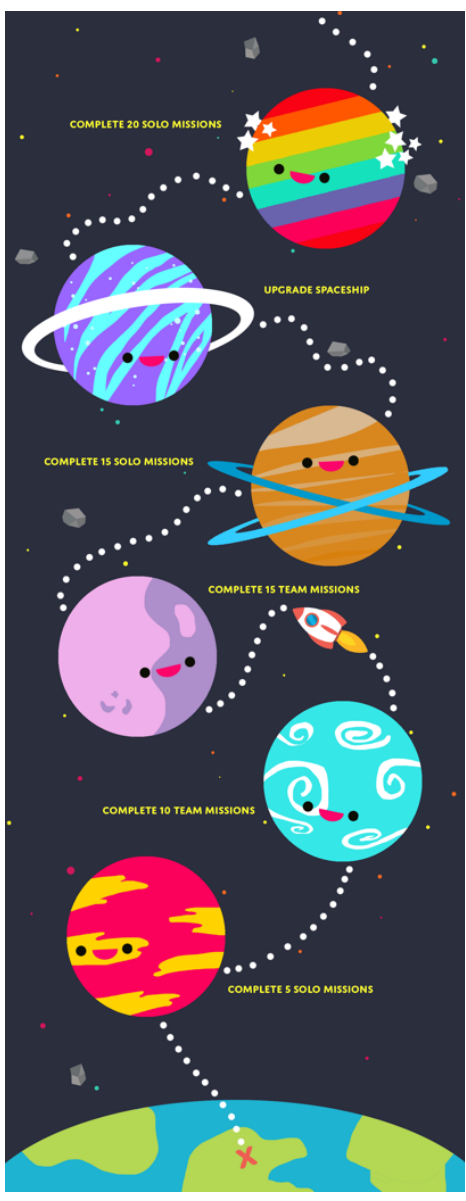

Figure 3: Space Theme App Graphics

\section{Space Explorer}

I added a storyline to make the app playful, which can assist the child to "....construct 
meaning and identity, to develop skills and to learn" (Birch \&

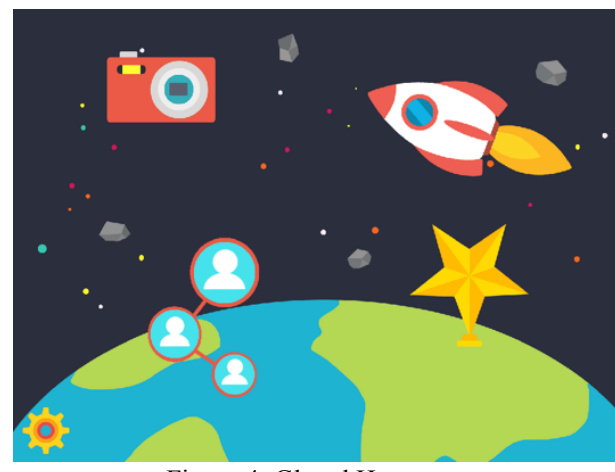

Figure 4: Glopal Homepage
Parnell, et al., 2017, p. 250). The storyline that I created for them, when they first use Glopal, is that each user is a space explorer on a mission to learn more about planet Earth. We can use "multimedia rich digital stories to be powerful learning tools for instruction across... subjects" (Campbell, 2012, p.

387). If we immerse the child into this position of play, there is a better chance for them to feel more excited about using the app. They will be introduced to their homepage, which is a bird's eye view of planet earth and five buttons they can click on: a camera to take photos, a spaceship to enter the mission space, a social icon to see their Glopals, a star to track their progress and rewards, and a settings button to adjust their username and privacy settings. I use "play as a dialogical space where players engage in creative communicative action" (Birch \& Parnell, et al., 2017, p. 251). Group missions disguised as adventures, achievements being won, all contribute to the "play" experience which will make the app more fun and engaging.

\section{Glopals}

As the kids work on these missions together, they will automatically obtain new Glopals, which are friends they have worked on missions with. This will allow for a deeper sense of connection, as they will be able to see if their Glopal is working on other missions they may want to join in on as well. Because the app is solely focused on photo based interactions, it is going to be a difficulty to communicate with one another. I have decided that the main purpose of the app is not to be a social messaging application, due to barriers such as language, safety, and confidentiality. I believe that with only photography can these kids develop a sense of connection and community through the act of participating in a shared mission. There may be an 
opportunity to expand the Glopal app in the future to develop a messaging feature, but the focus for the initial design will strictly be photo based.

\section{Design Functions}

Another crucial part in the posting process, is that each photo will be caption-less. What this does is ensure that there are no language barriers, and it also leaves photos up to interpretation. Having a caption-less feed also gives a unified look, that makes scrolling through the images look like they belong together. On the Glopals page, kids will be able to see how many countries they have friends from, which will be fun for kids to see and show how many Glopals they have from all over the world. Their usernames will have their countries flag(s) beside them, to indicate what country they are from. The colors that I chose to design the app logo are blue and yellow. Blue signifies "rust, loyalty, wisdom, confidence, intelligence, faith, and truth," while yellow "produces a warming effect, arouses cheerfulness, \& stimulates mental activity" (Colour Wheel Pro). These colors are a fun combination that works

well for the design of a kids app.
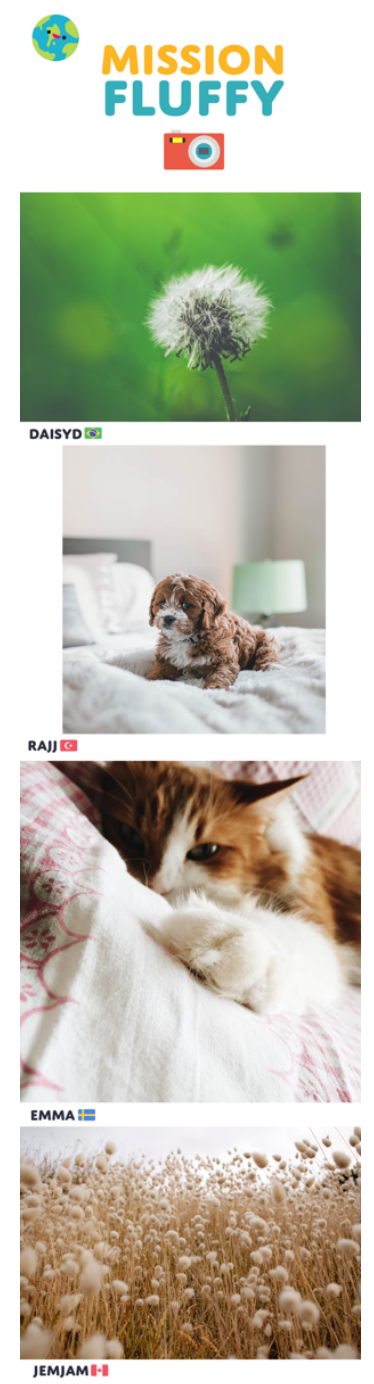

Figure 5: Mission Fluffy

When looking at designing an app for children there are a few key design elements that need to be considered: feedback, affordances, and signifiers. It is crucial for kids to obtain feedback, which is defined as "communicating the results of an action", when interacting with a device (Norman, 2009, p. 23). What this creates is better understanding towards the actions they are doing, plus it allows for a bunch of possibilities to making the interaction with the app fun. For example, if a child were to take a photograph and there was no camera click sound following the action of taking a photo, this would be a non-satisfactory experience. In order to make it fun, 
the feedback for the camera could be customizable, like animal sounds, or a fun tune.

It is important to keep the feedback consistent, in order for kids to learn how to use the app quickly (Gelman, 2014). Affordances “determine just how the object could possibly be used" (Norman, 2009, p. 11). Kids need big signs, and clear icons that will assist the child in navigating through the app (White, 2016). For example, to enter a new menu, an image of a door can be used as an affordance for 'entering'. Signifiers go hand in hand with affordances since they "communicate where the action takes place" (Norman, 2009, p. 14). For example, to open a specific door, an arrow could be used to signify which door to open. Alongside these three design elements, it is important to make the app colorful, which will call for engagement and excite the child when using it (White, 2016). Designing for kids is a whole different process that takes a lot more out of the box thinking, since children obviously do not think and interact the way adults do. But it helps to know these specific design elements to assist as the main structure for my prototype.

\section{Parent/Guardian Monitoring}

The app will have two access points, one for the child to use the app and the other for a parent/guardian, or educator to monitor the child's interactions and posts. By having a parent/guardian participate in this exchange, even through the backend of the app, they "...can provide children with a sense of audience, share interests and narratives, talk with children about their [photos] or involve themselves in joint [photo] activities with them." (Lenhart, 2012). It is also important to keep in mind that the person allowing the child to have access to this app is the parent/guardian. We need to keep them involved and participating. This creates opportunities for conversation about the world and other cultures beyond the scope of the Glopal application, between the parent/guardian and the child. Even though children may have a developed media 
literacy “...technology needs to be supported by strong teachers, motivated learners and sound pedagogy" (Third. et al., 2017, p. 48). An application like Glopal for parents/guardians, can be seen as an investment into their child's future, since this type of digital interaction can be beneficial for their child's development (Horst, 2010). Through the app, parents/guardians will be able to accept or decline photos before their child puts it up. They will be able to follow their child's interaction through a notification feed. They will also be able to see what missions their child has participated in, which they could help them with completing. This parent/guardian and child interaction is crucial to the Glopal application, because it allows for continuous exploration of how we learn about different cultures around the world. If the parent/guardian can be a part of this experience, it will enhance what the child takes away from this application because they can develop this global viewpoint together.

\section{Research Methodology: Limitations and Future Direction}

\section{Limitations Within Research}

Below is the research protocol that I have created for the use of future product development and further developing my research theories. This has already gone through Ryerson REB process. Due to time constraints from REB deadlines and re-submissions, I was unable to conduct my focus groups. Below is the design of a methodology that would allow me to gather both generative and evaluative data to further build my project that is currently at a MVP stage.

\section{Research Questions}

The major research questions that I will be unpacking throughout my research are:

1. How can I organize a shared digital space in a way that would facilitate a 
development of a meaningful intimate relationship for children from two different cultures?

2. What mechanism can be created that would help eliminate cultural difference from the discussion when creating relationships with other people?

\section{Procedures}

a) For the purpose of my research, I will be conducting a qualitative study. My method of research would be focus groups, semi-structured interviews, participatory action research, and user testing. There will be 3 different stages to my research. The first stage would be the first set of focus groups. One for the parent/guardians and the other for the children. This will take place within the first week of the 6 week project. The third week will include individual semistructured interviews for each parent/guardian and child pair. Lastly, I will end off my research with a final focus group in week 6 but this time parents/guardians and children will be in the same room. Throughout the 6 weeks, participants will be engaging in a photo exchange project with their photo pal that I will set them up with.

\section{i) Focus Groups:}

I will be conducting two focus groups in the first week of my research on the same day, one with children, one with their parents/guardians. I will be conducting the first focus group with 5 children and the other with 5-7 parents/guardians. The reason why I have chosen to do a focus group is to get a conversation started on the research questions I have developed and on larger conceptual ideas/to collect insight on (a) objectives, (b) safety concerns, (c) to establish procedures for how the exchanges will be carried out through email. Email is the chosen method of exchange since it allows for direct, private, confidential communication and photo sharing. The prototype won't be functioning yet, so this is the best method to simulate the photo sharing 
process. Focus groups are also a good way to obtain initial information to focus on through one focus group session, rather than multiple interviews. It would also help to see any patterns that would come up. My objective for the children's focus group is to see the way in which children express their thoughts and develop meaning relationships. My objective for the parents is to see what their goal for their child is within this project.

Focus group sessions are also a lot more fun and stimulating (Stewart et al., 2011), especially with children. I would be able to create a safe and collaborative space for them to be able to express their ideas. To establish a safe environment, I would host the focus groups in a visibly and aurally private conference room within a community center or a booked room at the Ryerson Student Learning Center that is central to the children's locations. Focus groups would also allow for a gamification process to collecting information, since children tend to have short attention spans and holding their attention would be easier if they are having fun (Stewart et al., 2011). There is a risk that the children may be too shy to talk in front of groups, in this scenario I will provide method of communication by using images such as a thumbs up or thumbs down sign and a written notepad to communicate their thoughts. In order to break the ice for the children, I will have them participate in an icebreaker and allow for them to personalize their own name tags. At the end of the focus group, I will provide each child with a photo album to place the photos they will be taking throughout the 6 week process.

For the parents/guardian's focus group I would pose a lot more thought provoking questions since they are able to articulate their thoughts clearly. I would also provide name tags, they may also have the opportunity to customize their name tags as well, but it is not a priority. Parents/guardians may have their minds at ease to see other parents/guardians being invested in this project. Within this focus group, I will have the parents/guardians assist in developing ways 
to protect their children from potential harm through the photo exchange process. It is important to "...acknowledge that parents and other adults in gate-keeping roles" (Graham et al.,2013, p. 65). During this focus group, I will be focusing more on the separate goals the parents would want from this, aside from the children, and my own.

For both focus groups, I would situate the participants in a circle since, "circles create a democratic environment and allow for equal eye-contact and interaction" (MDI). I will also make sure the consent forms are handed out with detailed explanation of the process before the focus group is conducted. I will also provide peanut free snacks and beverages during the focus group. Each focus group will be conducted over a 40 minute period and to ensure that it is kept within that time period, I will develop an agenda for each focus group. During these focus groups, I will distribute the contact information of the children's photo pal and the schedule of themes for each week. Since this is pilot development stage for my research, I will be unable to interview the children on the other end of the process. This is due to potential language barriers and distance in location. After this research process, I will look into reaching out to those participants. But for the sake of this initial research stage, I will be focusing on the children here in Toronto.

After the final week of the process, I will conduct a final focus group with the same participants as before. I will follow the same structure as before, but this time parents/guardians and children will be in the same room. This will allow to hear the shared experience between the parent/guardian and child duo. This will also be where children and parents/guardians will share their received photos with one another and share their understanding of the process. This focus group will heavily rely on the participant's experience and what they have to say about it. I will also bring in the Glopal prototype for the children and parents/guardians to be able to test out. 
This is where I will obtain feedback to further the development of the application. I expect this focus group to span over a 60 minute period.

\section{ii) Semi-structured Interview:}

The semi-structured interview will be conducted at the halfway point (Week 3) in order to check in with the children and the parents/guardians on their findings and observations. These interviews would be conducted with both the parent/guardian and child present in the room. It is important to have the parent/guardian there since this experience is not just with the child alone. In order to ensure that the parents do not take over the entire interview, I will be sure to make questions directed specifically towards the child (Stewart et al., 2011). These interviews will take place in the home of the participant. This will allow for comfortability with the child, and it would be convenient in time and location. It would also be a very private location. If participants are uncomfortable with this option, I will secure a room within a community center or a booked room at the Ryerson SLC to do the interview. The semi-structured interview would only take about 20 mins to do a general check-in with the participants. The objective for these semistructured interviews is to see if I need to alter the type of themes that are given and obtain initial responses to the photo exchange process.

\section{iii) Participatory action research:}

The children and parents/guardians will be partaking in a photo exchange with another child and parents/guardian from another country through email. Participatory action research, "seeks to understand and improve the world by changing it" (Baum et al., 2006, p. 854) and by doing this photo exchange process I will be able to see how we can alter the way in which children develop intimate encounters with those in another country. This method of research gives power to the participant. It works to empower the participant and the actions they choose 
(Baum et al., 2006). This "movement challenges the system of surveillance and knowledge control established through mainstream research" (Baum et al., 2006, 855). Throughout the process, I will be giving the power of facilitating the process to the parent/guardian and child and having them guide me through my research. My objective in this, is to see if intimate, meaningful relationships have been created, or at a smaller scale, if the child feels any closer to their photo pal since the start.

\section{iiii) User Testing:}

Since I have been able to develop the Glopal prototype through landscape research, I will have the kids play around with the application during the last focus group. I will be able to see what they like about the application after going through the photo exchange experience. Kids and parents/guardians will have their own iPad to test on, so they can individually focus on using the app. They will be in the same room, so they can discuss their experience together. During this process, I will not interfere and only ask open-ended questions after they are done testing the app, to gain insight on their interaction. I will be collecting ideas and critiques from both parents/guardians and children on the prototype and using their feedback to further develop the next stage of the application.

\section{b) Role of Researcher}

My role as a research would be a strictly observational role. I want to be led by my subject, as a researcher and developer. It is important for me to give power to the children and their parent/guardian. My biggest responsibility is protecting research participants from any physical, emotional or social harm. With that I will make clear in consent forms that participants are able to back out from the process at any time. I will also make available any services that can help 
deal with any emotional physical, emotional or social harm. As a researcher I will also be there to provide the initial connection with the children and their photo pal.

\section{Future Direction}

What I hope to gain from this research is the information that will allow me to further develop my prototype. I look at startups like The Rumie Initiative, who have developed products that align with what Glopal is trying to achieve. They have been able to digitally connect kids from around the world and given them an opportunity to receive a fulfilling education and life experience. They “...bring the surge of free learning content available online to communities least likely to access it but with the most to gain" (The Rumie Initiative). I hope to collaborate with them to bring Glopal to those countries that do not have access to digital devices or internet. I also see this application being used in school systems as a part of a curriculum. It would prove to be most successful in a school setting, since kids can collaborate and discuss on their findings together. In Experience in Education, John Dewey (1938) talks about how experiences in students' everyday lives make the most meaningful subjects. If we take on this idea and apply it with the Glopal app, we can use this digital but also 'hands-on' approach within the education system, to help deliver this learning experience to kids. Schools are the perfect place to launch the app because "programs are still relatively sparse in media...production-oriented education...however, there seems to be a growing recognition of their importance" (Lange \& Ito, 2010, p.247). Schools also allow for media accessibility that kids may not have access too, especially in less fortunate countries (Lange \& Ito, 2010). Educators can use the app as a teaching tool for assignments and giving kids a real life interactive experience. 


\section{Conclusion}

I understand that my app alone will not be able to solve these issues. But if it can make a small impact into the future of these children, and be an experience that they will remember, that is all that I can hope for. We look at all that is going on around us in our world today and have to work towards making it a place that we are proud to live in. With technology being a part of kids' lives, we need to be able to provide them with the tools to help guide them into becoming global citizens. With Glopal I hope to create this opportunity for kids to become more open minded, self-aware, and empathetic towards one another. As technology advances, humanity should too. Through the use of Glopal, I hope it can help change the way kids see the world, one photo at a time. 


\section{REFERENCES}

Baudrillard, J., \& Foss, P. (1983). Simulations (p. 2). New York: Semiotext (e).

Baum, F., MacDougall, C., \& Smith, D. (2006). Participatory action research. Journal of Epidemiology and Community Health, 60(10), 854-857. Retrieved on Feb 18, 2018. http://doi.org/10.1136/jech.2004.028662

Birch, J., Parnell, R., Patsarika, M., \& Šorn, M., (2017) Creativity, play and transgression: children transforming spatial design, CoDesign, 13:4, 245-260, Retrieved on April 30, 2018 from DOI: 10.1080/15710882.2016.1169300

Campbell, Terry A. (2012). Digital storytelling in an elementary classroom: Going beyond entertainment. Procedia: Social and Behavioral Sciences. Retrieved on April 30, 2018 from doi:10.1016/j.sbspro.2012.11.424

Childs, M. (2016). Reflecting on translanguaging in multilingual classrooms: Harnessing the power of poetry and photography. Educational Research for Social Change, 5(1), 22-40. Retrieved on Oct 11, 2017 from http://ezproxy.lib.ryerson.ca/login?url=https://searchproquest-com.ezproxy.lib.ryerson.ca/docview/1788992946?accountid=13631

Colour Wheel Pro. (n.d). "See Colour In Action". Color Wheel Pro. Retrieved on April 16, 2018 from http://www.color-wheel-pro.com/color-meaning.html

Dewey, J. (1938). Experience and education. New York: Macmillan.

Essentialism. (2018). In OxfordDictionaries.com. Retrieved on July 19, 2018 from https://en.oxforddictionaries.com/definition/essentialism

Freire, P. (1972). Pedagogy of the oppressed. Harmondsworth, UK: Penguin. (as cited in Childs, M. (2016).

Gelman, Debra Levin. (2014). Design for kids. Brooklyn, NY: Rosenfeld Media.

Graham, A., Powell, M., Taylor, N., Anderson, D. \& Fitzgerald, R. (2013). Ethical Research Involving Children. Florence: UNICEF Office of Research - Innocenti.

Haslam, Nick., Basian, Brock., Bain, Paul \& Kashima, Yoshihisa. (2006). Psychological Essentialism, Implicit Theories, and Intergroup Relations.Group Processes Intergroup Relations. 9:63. Retrieved on July 19, 2018 from DOI: 10.1177/1368430206059861

Hebert, T. (2010). Crafting moments of inspiration in the classroom. Kappa Delta Pi Record, 46(4), 148-151. Retrieved on Oct 11, 2017 from https://journals-scholarsportalinfo.ezproxy.lib.ryerson.ca/pdf/00228958/v46i0004/148_cmoiitc.xml

Horst, Heather A. (2010). From MySpace to Facebook: Coming of Age in Networked Public Culture Hanging out, messing around, and geeking out : kids living and learning with new media. 92-117. Retrieved on April 30, 2018 from 
https://www.researchgate.net/publication/234828876_Hanging_Out_Messing_Around_a nd_Geeking_Out_Kids_Living_and_Learning_with_New_Media

Lange, Patricia G \& Ito, Mizuko. (2010). Creative Production. Hanging out, messing around, and geeking out : kids living and learning with new media. 243-257. Retrieved on April 30, 2018 from

https://www.researchgate.net/publication/234828876_Hanging_Out_Messing_Ar ound_and_Geeking_Out_Kids_Living_and_Learning_with_New_Media

Lindberg, S., Warnestal, P., Nygren, J. \& Svedberg, P. (2014). Designing Digital Peer Support for Children: Design Patterns for Social Interaction. Proceeding IDC'14 Proceedings of 2014 conference on Interaction design and children, 47-56. Retrieved on Feb 18, 2018. Doi: $\underline{10.1145 / 2593968.2593972}$

Lenhart, Amanda. (2012). Downloading Apps For Children. Pew Research Centre. Retreived on June 1, 2018 from http://www.pewinternet.org/2012/05/15/downloading-apps-forchildren/

Maddox, Brittney. (2017). Examining Racist Tropes In Disney Animated Films. Medium. Re trieved on Retrieved on April 16, 2018 from https://medium.com/@nerdypoc/examiningracist-tropes-in-disney-animated-films-562279a9565a

Maddox, Brittney. (2017). Examining Racist Disney Tropes II. Medium. Retrieved on April 16, 2018, from https://medium.com/@nerdypoc/examining-racist-disney-tropes-continueda5379acc5783

McCormack, Brian. (2002). Postcolonialism in an Age of Globalization: Opening International Relations Theory to Identities in Movement. Alternatives: Global, Local, Political, 27(1), 99-115. Retrieved on April 16, 2018 http://www.jstor.org/stable/40645038

McLean, Scott. (2005). The Basics of Interpersonal Communication. Boston, MA: Allyn \& Bacon.

MDI. (n.d). Resources: Conducting Focus Groups with Children. MDI. Retrieved on Feb 18, 2018. on http://www.discovermdi.ca/focus-groups-children/

MET. (2017). Talking Pictures: Camera-Phone conversations between Artists. MET Museum. Retrieved on Dec 6, 2017 from https://www.metmuseum.org/exhibitions/listings/2017/talking-pictures

Pariser, Eli. (2011). The filter bubble: What the Internet is hiding from you. Penguin UK. (p1-20).

Richards, Rosemary D. (2009). Young visual ethnographers: children's use of digital photography to record, share and extend their art experiences. International Art in Early Childhood Research Journal, Volume 1, Number 1. Retrieved on April 30, 2018 from 
http://artinearlychildhood.org/artec/images/article/ARTEC_2009_Research_Journal_1_A rticle_3.pdf

Rey, Eddy Borges. (2015). News Images on Instagram: The paradox of authenticity in hyperreal photo reportage. Digital Journalism. 571-593. Retrieved on Dec 6, 2017 from http:// www.tandfonline.com.ezproxy.lib.ryerson.ca/doi/abs/10.1080/21670811.2015.1034526

Rumie Initiative. (n.d.) Rumie Initiative. Retrieved on April 30, 2018 from https://www.rumie.org/

Wells, G. (2000). Dialogic inquiry in education: Building on the legacy of Vygotsky. In C. D. Lee \& P. Smagorinsky (Eds.), Vygotskian perspectives on literacy research: Constructing meaning through collaborative inquiry. 51-85. Cambridge, England: Cambridge University Press. Retrieved on June 13, 2018 from https://people.ucsc.edu/ gwells/Files/Papers_Folder/Building\%20on\%20Vygotsky.pdf

White, Becky. (2016). Designing For Kids Is Not Child's Play. Smashing Magazine. Retrieved on Feb 28, 2018 from https://www.smashingmagazine.com/2016/01/designing-apps-forkids-is-not-childs-play/

Said, E. W. (1978). Orientalism. New York: Pantheon Books.

Sawant, Dr. Datta. (2011). Perspectives on Post-colonial Theory: Said, Spivak and Bhabha. Literary Endeavor. 2. 129-135.

Serriere, S. C. (2010). Carpet-time democracy: Digital photography and social consciousness in the early childhood classroom. The Social Studies, 101(2) Retrieved on Oct 11, 2017 https://journals-scholarsportalinfo.ezproxy.lib.ryerson.ca/details/00377996/ v101i0002/60_cddpascitecc.xml

Stewart, D. W., Shamdasani, P. N. \& Rook, D. W. (2007). Applied Social Research Methods: Focus groups. Thousand Oaks, CA: SAGE Publications Ltd Retrieved on Feb 18, 2018. doi: 10.4135/9781412991841

Stokes, Patricia D. (2006). Creativity from Constraints the Psychology of Breakthrough. Springer Pub. Co.

Third, A. et al. (2017) Young and Online: Children's Perspectives on Life in the Digital Age (The State of the World's Children 2017 Companion Report). Sydney: Western Sydney University. Retrieved on April 30 from DOI: 10.4225/35/5a1b885f6d4db 